\title{
Laboratório de humanidades: percurso estético literário como dinâmica humanizadora na saúde
}

\section{Laboratory of humanities: literary aesthetic journey as humanizing dynamics in health}

\author{
JacQUeline IzUMI SAKAMOto* \\ Dante Marcello Claramonte Gallian*
}

Resumo: Este trabalho integra o Projeto de Pesquisa Regular FAPESP As Patologias da Modernidade e os Remédios das Humanidades: investigação e experimentação e tem como objetivo apresentar o papel das Humanidades como caminho de humanização efetiva no âmbito da saúde, partindo de uma experiência educacional concreta: - Laboratório de Humanidades, em especial, em seu percurso estético literário compreendido com base no referencial teórico de Mikhail Bakhtin, na dinâmica entre fruição de obras literárias e repertório filosófico conjugados.

Palavras-chave: laboratório de humanidades, humanização em saúde, literatura e medicina

Abstract: This study is part of the FAPESP Regular Research Project The pathologies of modernity and the remedies from humanities: investigation and experimentation and has also the purpose of presenting the role of Humanities as a way of effective humanization within the health scope, starting from a practical educational experience: the Laboratory of Humanities, particularly, in its literary aesthetic journey, based on the theoretical framework by Mikhail Bakhtin, in the dynamics between the enjoyment of literary works conjugated with philosophical repertoire.

Keywords: humanities laboratory, humanization in health, literature and medicine

\footnotetext{
Doutora em Saúde Coletiva pela EPM/UNIFESP. Pedagoga e Mestre em Ciências da Religião pela PUC/SP.

** Diretor do Centro de História e Filosofia das Ciências da Saúde (CeHFi) da Universidade Federal de São Paulo (UNIFESP). Professor-orientador dos Programas de Pós-Graduação "Ensino em Ciências da Saúde" do CEDESS da UNIFESP e "Saúde Coletiva" do Departamento de Medicina da UNIFESP.
} 


\section{ntrodução}

Este artigo apresenta parte dos resultados de pesquisa ${ }^{1}$ que integra a vertente experimental do Projeto de Pesquisa Regular FAPESP (10/50448-0) As Patologias da Modernidade e os Remédios das Humanidades: investigação e experimentação. O projeto propõe um percurso heterodoxo de formação partindo de uma experiência empírica concreta, o Laboratório de Humanidades (LabHum) desenvolvido pelo Centro de História e Filosofia das Ciências da Saúde (CeFHi) da UNIFESP/EPM. Experiência estética literária que não se limita fundamentalmente como racional cognitiva, mas que leva em consideração outros aspectos da existência humana, e que busca unificação das experiências de vida e da cultura ampliando as concepções de humanização na área da Saúde.

\section{Laboratório de Humanidades (LabHum): vertente experimental do Projeto}

O Laboratório de Humanidades é uma atividade que reúne ao mesmo tempo: disciplina de Graduação (medicina, enfermagem, fonoaudiologia e ciências biomédicas), disciplina de Pós-Graduação para programas do campus São Paulo e atividade de extensão e abertura aos participantes livres (funcionários e membros da comunidade UNIFESP). Em desenvolvimento desde 2003 na Escola Paulista de Medicina/ UNIFESP foi ganhando corpo até a forma em que funciona hoje: como um grupo de reunião semanal onde são discutidas obras da literatura clássica, moderna ou antiga, como repertório humanizador e formativo para profissionais da área da Saúde.

Com uma metodologia clara e amadurecida ao longo de mais de dez anos, o papel fundamental do coordenador e a disponibilidade de seus participantes, o LabHum alia a promoção da subjetividade ao rigor intelectual, a formação humanística e a descontração no encontro entre profissionais e pesquisadores da área da Saúde (BITTAR; SOUSA; GALLIAN, 2013). A dinâmica se constrói em ciclos semestrais que comportam a leitura de um a dois livros por semestre. As obras são escolhidas pelos coordenadores e devem ser previamente lidas pelos

1 Tese de doutorado no Programa de Pós Graduação em Saúde Coletiva EPM/UNIFESP com apoio FAPESP, processo $n$ ㅇ 2012/ 10176-6. 
participantes. Os encontros são semanais e têm a duração de noventa minutos, sendo que a carga horária total de cada ciclo é de vinte e oito horas

A primeira fase da dinâmica é chamada de história de leitura, suscitada pela leitura individual que permite a cada participante trazer afetos e impressões causadas pela primeira leitura. Terminada esta fase, o coordenador elabora e propõe um itinerário de discussão, fase mais extensa do ciclo na qual trabalhará núcleos temáticos, personagens, valores emergentes das histórias de leitura. Aqui as discussões normalmente remetem a situações da vida pessoal e profissional, levando os participantes a reverem suas próprias posições. As histórias de convivência fecham o ciclo de leitura e discussão de cada obra e encerram o itinerário de discussão. Nesta fase é solicitado a cada participante que exponha uma análise livre e pessoal da experiência que vivenciou, tanto da leitura quanto da discussão e compartilhamento no grupo (BITTAR; SOUSA; GALLIAN, 2013).

Para os alunos de graduação e pós-graduação, um relatório é solicitado ao final do ciclo como requisito para validação de créditos acadêmicos. Nele, cada participante realiza de forma livre e por escrito uma análise da experiência não compartilhada na discussão, na qual pode reunir de maneira mais elaborada uma síntese relacionada à leitura, à discussão e à reflexão no ciclo.

Os relatórios apresentados no período 2011-2012 foram eleitos como fonte principal de elaboração deste trabalho, e a fim de garantir o anonimato dos participantes, a identificação foi assim estabelecida: semestre/ ano/ número do relatório. Nos relatórios encontramos referências aos personagens das obras lidas, porém, o conhecimento da obra não é indispensável para a compreensão do sentido atribuído neste texto, pois se trata de um relato a partir, e não sobre, as obras lidas. $\mathrm{O}$ que resultou numa discussão que dialoga com fundamentos teóricos em consonância com o percurso estético literário compreendido como formação humanizadora, conforme apresentamos a seguir.

\section{Literatura Clássica no Laboratório de Humanidades}

Tantas foram as formulações que pretenderam, e ainda pretendem, subordinar a literatura às formulações gerais e abstratas, ainda que reconhecendo seu status de conhecimento, que mais nos levam a dissecá-la do que à paixão da leitura propriamente dita. Por outro lado, não seria a aspiração da literatura 
mais simples, e ao mesmo tempo mais complexa, uma maneira de compreender a experiência humana? (TODOROV, 2010; COMPAGNON, 2009). Diríamos então que, no lugar de formulações gerais, a literatura compreende o singular preservando a riqueza e o risco do vivido. E sua grandeza está em nos dar a ver o que não enxergamos (FINKIELKRAUT, 2011).

A literatura, assim como o escritor, é mais livre dos condicionantes a que outras áreas do conhecimento se subordinam, e está dispensada do peso das expectativas que uma disciplina científica demanda, transitando com maior liberdade. Ao contrário da maneira com que a cultura hoje vê o mundo: composto de partes separadas, um descontínuo, uma série de combinações sobre números finitos e circuitos que se ligam aos transistores em nossa calota craniana. Por sua vez, a literatura é mais afeita às tradições e aos elos geracionais e históricos, preserva um continuum como um fio que desenrola, da obra para a vida. Não exclui as experiências vividas, mas antes, recoloca mundos em continuidade onde nos percebemos ligados na cadeia dos homens e da história (CALVINO, 2006; TODOROV, 2010).

A obra literária nos revela a nós mesmos. Pelas experiências vividas, trazemos nossas próprias experiências de vida à tona.

Foi-me impossível deixar de fazer a analogia com minha própria história. Dante (Cf. ALIGHIERI, 2012) começa seu percurso perdido "no meio do caminho da vida", e na resolução deste conflito precisa entrar no inferno, reconhecer tudo que há lá dentro. Também eu me apresentava no "meio do caminho", com pouco mais de 40 anos, e com muitas dúvidas quanto a como seguir adiante; mas sempre relutei em entrar em meu "inferno" interior, talvez da mesma forma como sempre relutei em ler esta obra. E, no entanto, é essencial penetrar nos domínios sombrios, trazer à tona os sofrimentos que ali se apresentam encará-los, reconhecê-los, e superá-los - pois este caminho só faz sentido quando é passagem para o Purgatório (reino de negociação) e, finalmente, para a estação de tranquilidade e bem estar no Paraíso. Desta forma, a leitura do livro vai nos deixando face a face com nós mesmos. Cada paisagem desoladora, cada personagem encontrada, com suas histórias, suas mazelas e seus sofrimentos, nos traz sentimentos, julgamentos, e reflexão: e a humanização parece aflorar internamente, na perspectiva de que o autoconhecimento possibilite a mudança de rumo de nossa própria vida. Humanização aqui entendida como permitir que aflorasse o humano dentro de 
nós, deixando de lado as máscaras e os comportamentos socialmente "esperados". Poder observar nossa história, refletir sobre nossa vida: perceber os pontos que precisamos melhorar, os nossos sofrimentos, as atitudes negativas que repetimos por vezes de forma inconsciente, bem como as situações que já melhoramos. Ou seja, visitar desassombradamente nosso inferno, sabendo que podemos sair dali para viver melhor. (1/2011/R 21)

O inesperado: começamos a ler e somos lidos em relação à obra (CALVINO, 1993). Isto se dá porque a literatura não está submetida à tutela da objetividade e neutralidade como nas ciências. Assim, na medida em que "O poeta não usa descrições do mundo; ele próprio participa de sua criação" (TARKOVSKI, 1998, p. 45), ele não se coloca num estado de indiferença que uma mera descrição possa vir a realizar. De modo que, ao final, nem o autor, nem o leitor poderão ser aquilo que eram ou acreditavam ser (STEINER, 2006). E uma vez que participam da criação, só o realizam colocando em jogo a própria pele. Aqui a literatura se diferencia enormemente de outras formas de experimentação prática que se realizam, como nas ciências, por exemplo, na pele alheia (CALVINO, 2006).

Num estado de indiferença, o leitor se torna mero espectador, sempre destacado do mundo. Alçar uma verdade a ser submetida a verificação será sempre mais confortável se realizado na pele alheia. Por outro lado, num estado dramático onde é a própria pele que está em jogo, o autor, ou a obra literária, não impõe ao leitor a elaboração de uma tese. Mas ao estabelecer com ele uma relação pessoal ao dar forma ao acontecimento, ele propõe e deixa o leitor livre e mais ativo, permitindo que responda melhor à sua vocação de ser humano onde o autoconhecimento possibilita a mudança de rumo da própria vida (CALVINO, 2006).

Dito de outro modo:

O fato é que este livro era para ser lido mais com as entranhas do que com a cabeça. E ler pelas entranhas é uma atividade bastante arriscada, na maioria das vezes elas são bem mais facilmente atingíveis do que a cabeça. Algo que o gerente, cuja maior qualidade era não ficar doente (talvez tivesse entranhas pouco atingíveis) certa vez alertara a respeito do coração das trevas: "Os homens que vêm para cá não deviam ter entranhas. (CONRAD, 2008, p.38). (2/2012/R 91) 
A questão se dá entre a preferência de compreensão ou a desistência de compreensão. O limiar está demarcado pela atitude da leitura que será decisiva (TODOROV, 2010). Cabe ao leitor levar a literatura a esclarecer sua força crítica, ainda que coloque a própria pele ou suas entranhas em jogo, porque a literatura nos concede intimidade, não exposição. Intimidade como um bem precioso de onde atamos laços que possibilitam uma interpretação personalizada, como limiar demarcado que sustentará uma atitude de leitura (CALVINO, 2006; TODOROV, 2010). Ou ainda, intimidade que não se permite ser confundida com uma fantasia refletida, mas chama à reflexão:

Sonhamos acordados algumas vezes em nossa vida, mas quem disse que não estamos apenas vivendo no mundo dos sonhos e um dia acordaremos dele. Quando nos olhamos no espelho, vemos ali a nossa imagem real ou uma imagem imaginária ou até mesmo de mentira. Será que somos apenas fantasias criadas por nós mesmos, e mostramos no espelho somente aquilo que aguentamos ver? A Literatura promove uma linguagem que nos aproxima em algumas vezes de nossa realidade, ou que nos faz refletir sobre nossa realidade. (1/2011/R 01)

Existe ainda uma força particular da obra clássica: ela nunca termina de dizer o que tinha para dizer e cada encontro é um acontecimento sempre novo (CALVINO, 1993, p. 11). Porém será necessário que a deixemos dizer sem intermediários. Nenhum comentador fala melhor da obra que o próprio autor, porque o efeito da leitura está em que a partir dela podemos nos deleitar com nossas próprias histórias. A obra clássica nos convoca a ouvir o mesmo chamado que levou o artista a criá-la.

Depois do sufocamento, da repressão, dos limites e normas do Admirável Mundo Novo (HUXLEY, 2009) eis que nos deparamos com o céu azul, o vento, o horizonte e o ilimitado Zorba, o grego (KAZANTZAKIS, 1973). Sua falta de freio, seu aparente desapego e descompromisso com tudo e todos, provocou desconcerto. Então, a sensação que tive ao ler Zorba foi o de ter saído de um lugar muito escuro e a claridade incomodou. (2/2011/R 23)

Como pano de fundo para as aventuras em séries de Zorba o autor nos mostra a vida como ela é, repleta de personagens como nós, que têm suas paixões, vaidades, amores, esperanças e mais outros sentimentos: inveja, vingança, 
mentiras, desesperança, bondade e compaixão, enfim, a essência humana e a capacidade de conseguirmos sentir todos eles, e no qual nos reconhecemos em alguma personagem ou identificamos características de alguém conhecido em outra. (2/2011/R 23)

O escritor nos permite transitar em cenários tão distintos sem autoacusações ou vergonha. Tão diferente do texto de um homem comum que somente afirma e repete à exaustão o valor de um ato personalizado. Homem comum que tenta controlar a maneira como será interpretado, sua história é só sua, e ele teme que percebamos outras nuances naquilo que diz. Mas, afinal, qual seria o valor de escutar seu próprio eco? $\mathrm{O}$ escritor, ao contrário, é mais livre e não busca controlar nem impor maneiras corretas de interpretação. Ainda que ele próprio tenha pontos fracos ou obscuros, sua obra ganha vida apesar deles (FREUD, 1908 [1907]; FORBES, 2010). Liberdade é aqui compreendida como "[...] aprender a exigir apenas de si mesmo, não da vida ou dos outros, e saber como doar: significa sacrifício em nome do amor" (TARKOVSKI, 1998, p. 217). Sem concessões, mas generoso, em suas histórias muitas outras passam.

Mas os sentimentos, emoções e entendimento por eles despertados já são partes inerentes de cada um de nós, de tal forma que, muitas vezes, já não podemos discernir onde eles terminam e onde começamos nós.

Alguns dos personagens invadiram literalmente nossas vidas (Cf. RODRIGUES, 2004, V.1), revelando emoções escondidas e possibilidades jamais sonhadas: "acho que não seria assim tão fácil matar meu marido". (1/2012/R 68)

O escritor não teme ser mal-entendido porque sabe que o equívoco é constitutivo de nossa humanidade. Sua segurança não vem da aprovação externa, por isso não faz concessões, mas antes de uma certeza constitutiva que o leva a dar forma ao espaço do sem palavra. A arte e o artista nos colocam diante de dimensões distintas, não raciocinam em termos lógicos nem formulam uma lógica dos comportamentos humanos. Um estado de alma, e não um método de pensamento. Se a compreensão na ciência diz respeito a um plano lógico demonstrável e repetitivo, na arte compreensão representa aceitação estética do belo: 
Em uma breve comparação a minha própria vida, naquele período eu parecida que estava meio que robotizado, mergulhado na rotina e no fazer sem pensar, sem refletir... Via-me nos personagens estáticos e sem questionamento. Identifiqueime e estarreci! Parecia que estava lendo sobre a minha realidade de vida. Tudo corrido sempre, sem momentos para reflexão, sem crítica, sem questionamentos. Acho que umas das grandes queixas do homem moderno é o estresse da contemporaneidade, trânsito, correria, tudo mecanizado, sem brilho, sem vida... O livro era o retrato que via em parte da minha vida e de nossa sociedade adormecida. Temos relacionamentos vazios, muitos se orgulham de possuir 2000 amigos nas redes sociais, mas de fato não possui um sequer. Vivemos num mundo cheio de pessoas vazias.

Aprendi que temos em nós um mundo de possibilidades, mas nossos olhos não estão treinados para ver beleza, soluções. O Admirável Mundo Novo (HUXLEY, 2009) pode estar em nosso interior. (2/2011/R 35)

A literatura clássica é mais afeita aos legados de uma tradição que acaba estabelecendo um grande confronto à ideia de um indivíduo autocentrado e gerador de si mesmo. Tradição aqui bem entendida como uma percepção do mundo que não estabelece fronteiras tão definidas entre homem e mundo, interno e externo, passado e futuro, mas antes recoloca mundos em continuidade.

Dentre tantas discussões realizadas, houve uma que chamou mais atenção: o processo de humanização comparado a uma cruz, que tende a levar aquele que o realiza para o alto mudando sua visão sobre o Homem (verticalização), mas que necessita da horizontalidade para permanecer com o humano e vinculado à realidade. Essa imagem é para que aqueles que optaram por entrar nesse caminho de reflexão e atitude não se sintam superiores aos demais. A humanização exige reflexão e atitude. Na falta de uma dessas realidades, o processo está falho. (2/2011/R 55)

Um legado que estabelece tensão continuamente entre absoluto e provisório e que possibilita refratar-se em experiência própria e única forjando um elo com toda a história da humanidade. O que torna a responsabilidade de cada um incalculavelmente maior ao abrir mão de uma lógica que busca completude onipotente na esfera da existência cotidiana para outra que se abre ao inacabamen- 
to. E que não vise a desconstrução pela desconstrução, mas antes, que preste consequência à liberdade de exigir somente de si mesmo (TARKOVSKI, 1998).

O encontro com ele foi belo e decepcionante para a minha sede de captura. Kurtz não se deixa capturar e no final do livro não sabemos muito bem o que aconteceu e quem era ele. Era um homem bom? Era um homem mau? Não consigo responder a nenhuma destas questões, o que me leva afirmar que o encontro não foi gratuito, talvez tenha aquietado um pouco a minha sede de captura-classificatória, ou como disse o "Russo": "Vou lhe dizer, exclamou, esse homem ampliou o meu espírito". (CONRAD, 2008, p.87) (2/2012/R 91)

A literatura nos desafia o tempo todo. Como lidar com a decepção diante de um personagem com contornos indeterminados? Buscamos a paz tranquilizadora do finito, numerável, classificável, um desejo de limitar o mundo. Uma defesa que talvez nos revele a incapacidade de lidar com o desconhecido, indefinido e não sistematizável, e que nos leva à construção de confortáveis fortalezas. Mas a tensão da literatura se dá na medida em que ela tenta escapar desta finitude, desta recusa em acreditar que nada possa escapar da razão e da ordem. Um esforço em exceder os limites da linguagem como um chamado daquilo que está fora do campo do tudo saber. A história humana é uma história esburacada e todas as tentativas de compreensão passam pela tentativa de recompor estes espaços. Existirá sempre uma parte oculta onde faltarão palavras para chegar, um vazio de linguagem que aspira por mais palavras (FORBES, 2010). A linha de força da literatura está em sua tentativa de dar palavra ao que permaneceu não dito. Ancorada neste impossível torna a vida mais real e menos prescrita (CALVINO, 2006). Diante do não saber, maior o movimento e maior o desejo de dilatar o mundo - "A satisfação de ir ao encontro com o outro (a própria obra literária e o grupo) para o encontro comigo mesmo" (1/2012/R 64).

\section{LabHum como uma cena - ou ato - dentro de nossa vida... (1/2012/R 60)}

Participar do LabHum como uma cena dentro de nossa vida muda as coordenadas de referência por considerarmos que é em cena que o ser humano se realiza, não mais rendido nem periférico, mas antes participativo e conectado, 
com seus acertos e erros. Cena como uma arena que tem como fundamento a potencialidade do diálogo, o princípio dialógico e humanizador, “[...] como o todo da interação entre várias consciências dentre as quais nenhuma se converteu definitivamente em objeto da outra" (BAKHTIN, 1997: 17).

Consideramos as duas novas concepções introduzidas por Bakhtin (1997) em seu Problemas da Poética de Dostoiévski, o autor monológico e o autor polifônico. Concepções fundadas em dois princípios opostos e irreconciliáveis: o monológico diz respeito ao teoricismo, a palavra fechada e morta da verdade abstrata; e o princípio polifônico que permanece aberto para a vida pela liberdade. No romance, o autor monológico é aquele que retém controle sobre seus heróis, que serão sempre objetos de representação como ferramentas nas mãos do autor, e os usa para expressão de sua própria verdade. Uma agressiva autoafirmação que no plano literário resulta na reificação do herói e do autor.

O autor polifônico, ao contrário, renuncia ao máximo ao controle sobre seus personagens permitindo a eles a busca de suas próprias verdades; em Dostoiévski a figura do autor se torna visivelmente ausente, expressão máxima da dialogicidade. Seus personagens não são objetos de seu discurso, mas antes sujeitos desse discurso diretamente significante numa autêntica polifonia de vozes plenivalentes (plenas de valor) e multiplicidade de consciências equipolentes (participam do diálogo em plena igualdade) que não se objetificam. Seus mundos se combinam numa unidade de acontecimento.

Para Bakhtin, Dostoiévski teve a capacidade de auscultar relações dialógicas em toda parte, penetrando toda a linguagem em tudo que tem sentido e importância. E neste aspecto estabelecemos correspondência entre as relações dialógicas como manifestações humanas (e humanizadoras) na dinâmica do LabHum como uma cena em nossa vida. Uma cena em oposição às relações puramente mecânicas, como um acontecimento vivo que irrompe no contato dialogado. Muito longe de estabelecermos uma teoria ou apresentarmos o percurso filosófico do autor, mas, antes, buscando equivalências pertinentes que possam trazer luz ao fenômeno Laboratório de Humanidades em sua dinâmica humanizadora, potencializada pelo repertório da literatura. Vejamos:

Por vezes digerimos ideias e visões anos a fio sem nunca termos pronunciado ou dado "forma" a elas até o momento que temos esta oportunidade (Laboratório de Humanidades) e lançamos ao meio, estas ideias ou crenças revestidas e formatadas 
em palavras, encontramos um eco que por vezes pode não ter nada a ver conosco e nos indagamos o porquê, destas ideias ter nos acompanhado e cristalizado até então em nós? (1/2011/R 05)

Ao considerarmos que a esfera da existência se dá na comunicação dialogada entre as consciências, o ponto de contato entre vozes será onde nasce e vive a ideia. Uma ideia na consciência individual isolada de outros homens degenera e morre. Somente quando contrai relações dialógicas com as ideias dos outros, é que ela começa a ter vida. Ou seja, recua, avança, se desenvolve, renova sua expressão, e mais importante, passa a gerar mais movimento, mais ideias (BAKHTIN, 1997: 86-87).

O pensamento monológico elucida e ordena seus objetos considerando o homem como magnitude final e definida, que poderá servir de base para a construção de qualquer cálculo. Do enfoque dialógico, ao contrário, resultará antes um mundo de consciências que se elucidam mutuamente. Sozinha, uma consciência não dá acabamento a suas ideias, ela precisa do confronto com outras, numa multiplicidade de consciências equipolentes que não se objetificam nem perdem sua personalidade, "pois a experiência de leitura é como uma impressão digital, única e sinuosa, ainda que mutável" (2/2011/R 52). Vida autêntica e única do indivíduo como uma impressão digital onde ele responde por si mesmo e se revela livremente (BAKHTIN, 1997: 6, 59, 87, 97).

Percebi o quanto a minha percepção do mundo havia mudado com as discussões e o quanto isso me libertava de uma tristeza que eu mesma me prendi ao longo de minha vida. (1/2011/R 12)

No plano monológico, a personagem é fechada e tem seus limites delineados pela visão do autor. Será seu sólido campo de visão, seus pontos de vista, que estarão inseridos na consciência da personagem como uma imagem definida da realidade. $\mathrm{O}$ autor polifônico, ao contrário, recusa todas essas premissas, no lugar de uma unidade definitiva do autor monológico, ele reserva à sua personagem a última palavra sobre si como um momento de sua autoconsciência (BAKHTIN, 1997, p. 51). O que se propõe aqui aos personagens, assim como aos participantes do LabHum, é a revelação de uma imagem humana resultante de sua consciência sobre si mesmos e o mundo. Toda a realidade se torna elemento 
de sua autoconsciência. Disto decorre uma posição valorativa e racional, o que o mundo é para o personagem e o que ela é para si mesma (BAKHTIN, 1997: 46-47).

Tanto Dante (Cf. ALIGHIERI, 2012) quanto Alice (Cf. CARROLL, 2012) permitem-se perdidos. Perambulam por lugares desconhecidos, perturbam-se com as situações, questionam, e algo os mobiliza a continuar sua caminhada. Ao entrarem em contato com as situações, permitem o despertar do ser cognoscente, permitem que algo os acrescente. Deixam a mensagem do quão é necessário assumir-se perdido, percebendo-se andar em círculos, andar com objetivo, mas perceber que, por muitos momentos, esse caminho toma-se árduo, onde o seu trajeto envolve encontros com momentos que maltratam o corpo e a alma. Em alguns momentos, as lágrimas chegam, assim como certo desânimo, mas é preciso caminhar, é preciso chegar ao que se propõe, é preciso acreditar para não sucumbir no fundo do espelho de si mesmo, no inferno da alma. E então, sente-se que existe odor no discurso das pessoas, algo que nos aproxima ou nos causa repulsa. A fala... O tom de voz... Alice se cansava dessa fala que nada dizia... Quantas vezes nos percebemos diante de falas vazias, não só de conteúdo, mas de significado, de ação. Nesse momento, encontro no livro A Divina Comédia essa linda frase (...) "acostuma teu olfato, pois convém acostumar o olfato ao mau cheiro. Assim não sofreremos tanto seus maus efeitos." (p. 48) A frase dita por Virgílio ao entrar no Inferno, remete a sensação de que tudo que nos causa um cheiro desagradável, por vezes é necessário que se adapte, para saber enfrentar, questionar, refletir e mudar quando necessário for. De nada adianta fugir. (1/2011/R 10)

Pleno diálogo em pé de igualdade onde Alice, Dante e Virgílio participam em coexistência com o relato sobre si e sobre o mundo do participante em cena. À consciência toda absorvente contrapõem-se outras consciências isônomas a ela. Sua palavra se encontra em íntima relação com a palavra do outro. Não se funde, conserva sua autonomia como palavra. E tudo se dá em movimento, nada é neutro: perambulam, perturbam-se, questionam, mobilizam, despertam, assumem-se, desanimam, acreditam, sofrem, sentem odores, adaptam-se. Sendo que o resultado de sua autoconsciência se volta precisamente para a "irremediável inconclusibilidade, a precária infinitude dessa consciência" (BAKHTIN, 1997: 50). 
O conhecimento se dá na base do diálogo, de uma consciência que segue em direção à outra consciência, onde percebemos duas possibilidades: uma consciência perdida dentro de sua polifonia interna, ou a consciência em diálogo com outra consciência. Tudo isto gera uma sensação de interpretação infinita, a fala está perdida no infinito. E diante deste infinito, como se poderia ter sobre o homem uma palavra final?

Ponto marcante da história de Nelson Rodrigues (2004, V.1) é a capacidade do autor em fazer com que todos nós nos sentíssemos, em algum momento do roteiro, incapazes de "julgar" qualquer um dos personagens, como se em cada um de nós houvesse um pouco de Alaíde, um pouco de Lúcia, um pouco de Pedro e um pouco de Madame Clessi. (1/2012/R 62)

Incapazes de dar a última palavra sobre os personagens que aqui já fazem parte da polifonia interna do participante, encontramos "[...] um enredo no qual vários abismos se relacionam. Essa condição de abismo, que se materializa no discurso febril das pessoas procurando a si mesmas, procurando construir teorias e definir processos morais e éticos [...]" (PONDÉ, 2003, p. 128).

Diante de tantos temas discutidos, algo fez muito sentido para mim neste semestre: enquanto acreditarmos que somos donos da verdade e que a nossa maneira de pensar é a única passível de ser aceita, estamos isolados dentro do nosso próprio mundo, deixando de perceber o outro e que essa dentre outras características, pode tornar nós profissionais da área da saúde, contribuindo mais para a desumanização do que para tornar nossa relação com as pessoas mais humana e principalmente poder nos aproximar e aprender muito com elas. (1/2011/R 19)

Quando acreditamos que "somos donos da verdade" acabamos por impor aos outros um sistema de constrangimento que acaba por nos isolar porque nenhum outro é compatível com meu critério último. E se mostra desumanizador na relação entre paciente e profissional da área da Saúde, na medida em que ao outro é confiscado seu status de ser falante. A polifonia, por sua vez, está imersa na materialidade da liberdade, onde não há critérios fixos e definidos à revelia, de onde decorre um problema: assim a palavra vai de um lado para outro, o que é de fato angustiante (PONDÉ, 2003, p. 137). 
Deste livro da Alice (cf. CARROLL, 2012) o que mais ficou para mim, é saber que temos a liberdade de escolhermos e argumentarmos, mesmo que seja para pessoas que não nos conheçam e que não nos compreendam, a argumentação é o que permite que sejamos nós mesmos, e muitas vezes para sermos nós mesmos e nos respeitarmos, temos que ter paciência e sabedoria para ouvir o próximo, talvez assim conseguiremos estar mais perto a tão aclamada humanidade no mundo atual. (1/2011/R 14)

A linguagem que não se pensa objetivante pode ser assim considerada: falar e deixar outro indivíduo falar, nunca fazendo deste outro objeto de sua fala. Isto contraria uma fé na autossuficiência de uma só consciência em todos os campos da vida, que é característica particular e estrutural da Idade Moderna, e que acaba por determinar todas as formas de manifestações de vida e criação. Assim, descarta a dissonância como uma contradição prejudicial dentro de um todo unificado num princípio de monotonia (BAKHTIN, 1997: 81).

Por outro lado, com Nelson Rodrigues e seu "Vestido de Noiva" (2004, V.1), ficou claro que a beleza da vida está justamente nas suas imperfeições e que o ser humano é naturalmente decepcionante e, talvez por essa característica, seja tão fascinante, tão real! (1/2012/R 62)

Para além dos critérios "o ser humano é naturalmente decepcionante", por não ser passível de objetivação, impossível chegar a um conhecimento último sobre ele. Sua autoconsciência vive de sua inconclusibilidade, de seu caráter não fechado e de sua insolubilidade. No enfoque polifônico o ser humano comporta contradições e controvérsias, a ele é dada a palavra, porém, não há síntese possível. Permanecer humano nesta perspectiva nos remete à ideia de produção contínua de conhecimento, eterna e infinita, que não chegará a um critério último, somente a mais polifonia. Assim, o homem deve passar pela agonia de não conseguir se definir, nem aos outros, de não conseguir ter a si mesmo nas mãos, porque ele mesmo se ultrapassa (PONDÉ, 2003, p. 128/133).

Uma posição dialógica e humanizadora afirma a liberdade interna, a falta de acabamento e de solução, e se realiza no momento do processo artístico, ou percurso estético, como "[...] o todo não-fechado da própria vida situada no limiar" 
(BAKHTIN, 1997: 63). Considerando que a questão humana não conta com uma existência autônoma, mas é dependente de outros transcendentes como valor:

Não é todo dia que encontramos Zorba (Cf. KAZANTZAKIS, 1973) em nosso entorno, e quando encontramos nos sentimos primeiramente desconfortáveis - sujeito bruto na forma, rude, já matou, lutou, estuprou. Se observarmos mais de perto, com atenção e sensibilidade, perceberemos homem sábio, lutador e de grande amor. Durante a narrativa, me senti com uma maior leveza de espírito e como o narrador - "Via, vivenciava com nitidez aquele espantoso espetáculo: eu me modificando".

[...] Imaginava quem da minha convivência se assemelhava à Zorba - amigos, familiares, pacientes - e conseguia aceita-los e entende-los melhor. Por exemplo, não era possível eu orientar uma pessoa que comeu, bebeu, teve sentimentos intensos (negativos e positivos) em sua vida inteira a ter uma alimentação saudável, uma vida regrada com o mínimo de estresse (do meu ponto de vista e do ponto de vista de uma pessoa que quer evitar doenças cardíacas), eu precisava achar um meio termo. Zorba possibilitou achar um caminho do meio, só pelo fato de aceitálo melhor e assim entende-lo. Existe também um pouco de Zorba em cada pessoa, por mais "narradora" que ela possa ser. (2/2011/R 25)

Ser "narradora" neste contexto significa ser como o personagem narrador do romance, que viveu muito teoricamente, mas, no contato com Zorba, foi se modificando. Personagem que, por não atender nenhum critério fixo, moral ou de valor, comporta nele mesmo todas as contradições possíveis, recolocando a polifonia de volta à vida. A impossibilidade de estabelecer sínteses sobre a condição humana ou sobre um personagem traz-nos um ganho, ainda que desconfortável. Aceitar a irredutibilidade do paciente, ou do personagem, devolve a ele a dignidade de existir como um outro que funda valor.

E nesse contorno todo, uma lição: parece-me que são as histórias que vivem através de nós (ou dos personagens do livro), ao invés de nós estarmos a criar. Parece-me que temos um ponto de mistério e que não podemos explicar. Tentar explica-lo é de alguma forma, querer garantias, racionalizar, operar e por assim dizer, apenas instrumentalizar a vida. (1/2012/R 64) 
Aqui retomamos a mudança de coordenadas de referência ao considerarmos "O LabHum como uma cena - ou ato - dentro de nossa vida" que traz a potencialidade do diálogo como fundamento da humanização na área da Saúde. Onde a impossibilidade de estabelecer sínteses nos leva diretamente à incapacidade humana de falar definitivamente. Isto nos coloca numa tensão produtiva entre o que conhecemos e o que não podemos conhecer. Dada a característica de inconclusibilidade, do caráter não fechado e insolúvel de nossa humanidade experimentada na dinâmica das discussões, identificamos uma estética que se revela ao presentificar o ainda não dito. Um acontecimento, ou ato, onde "A realidade toda - escreveu Dostoiévski - não se esgota no essencial, pois, uma grande parte deste nela se encerra sob a forma de palavra futura ainda latente, não-pronunciada" (BAKHTIN, 1997, p. 89).

É interessante notar que mesmo imersa há muitos anos no discurso corrente da humanização - com um desconforto ao qual faltava nome, somente agora ao finalizar o ciclo, percebo do que se tratava: muita coisa da prática cotidiana escapa à humanização, mas não por descuido. Talvez seja aqui, no termo 'escapa', que resida o que quero concluir sobre aquela primeira marca de minha jornada, a palavra.

Em quase todas as discussões do Laboratório, era este termo em que eu detinhame. Isto porque, em todas elas, algo sempre parecia escapar à palavra. Eu me perguntava: Não seria isso o que funda as humanidades? $\mathrm{O}$ fato de algo sempre escapar, não seria isso o que marca o ser humano? Entretanto, mesmo que não plena, mesmo que geradora de mal entendidos e desavenças, não há escapatórias! É pela palavra que nos diferenciamos dos outros seres. E então, não é isso (o que escapa) que nos torna humanos, marcando-nos de forma singular?

Dessa forma, a palavra é mesmo cheia de dissabores, a grande responsável pela humanização. (2/2011/R 26)

Diante da fundamental não coincidência consigo mesmo, enquanto vive o homem, não pode pronunciar a última palavra sobre si mesmo e sobre o mundo. $\mathrm{E}$ neste todo não-fechado, uma dimensão mais personalizada pode se abrir:

Por fim reflito sobre a vida autoral, aquela em que somos os escritores de verdade (como Alice é na obra), e não apenas peças manipuladas do xadrez. (Cf. CARROLL, 
2012) Traçamos nossa história de acordo com o que acreditamos e com o que queremos (ou podemos) enxergar.

A beleza está no que é real, e não na fantasia. Buscar utopias gera desesperança, pessimismo. O real, mesmo não sendo o ideal, é muito melhor do que o utópico simplesmente por existir. (1/2011/R 03)

A ação humana comporta um sentido de desconhecido e indefinido, de algo que não podemos nos apropriar: E é exatamente porque algo "escapa", destituindo as certezas definitivas, que o acontecimento do LabHum como ato humanizador possibilita uma expressão que é forma e movimento. A experiência estética da indeterminação enlaça as consciências no plano da criação, possibilitando escolhas responsáveis como efeito daquilo que "escapa". "Ao ler os dois livros, fica muito evidente de que não somos os donos da vida, mas somos responsáveis por nossas escolhas" (1/2011/R 10).

Assim, uma atividade criativa de leitura, com possibilidade de trânsito dialógico e original, acaba por convocar a consciência numa integração entre ética e estética. Ancorada num "ponto de mistério", a implicação na vida real se dá porque o ganho de sentido e valor acontece para cada um em confronto com outras consciências. Entre validades genéricas e a unidade do ato na tomada de cada decisão, encontramos uma força responsável. "Arte e vida não são a mesma coisa mas devem tornar-se algo singular em mim, na unidade de minha responsabilidade" (BAKHTIN, 2006: xxxiv).

\section{Considerações Finais}

O sentido e a proposta deste artigo se dá nesta dimensão estética literária e humanizadora que encontramos no Laboratório de Humanidades. No lugar de uma síntese definitiva, uma última palavra sobre si mesmo e o mundo, a vida nos parece mais afeita às contraposições dialógicas onde a polifonia leva a mais polifonia, possibilitando assim produção de conhecimento infinito sobre o homem e o mundo, mas sempre em devir.

Assumimos uma antropologia que comporta o caráter de inacabamento e inconclusibilidade, a coexistência e interação entre várias consciências que não se objetificam. Ponto fundamental nas relações entre profissionais da Saúde e 
pacientes, ambos considerados em sua dimensão de seres falantes e plenos de valor. Na medida em que o profissional da Saúde participa da experiência dialógica e polifônica no LabHum, acaba por estender esta dinâmica, esta percepção de si e do mundo, também na relação com seus pacientes: "A palavra humaniza, devolve a condição de dignidade a enfermos, por exemplo, permite a estes experimentarem dimensões que só poderiam experimentar pela via da palavra, estando impossibilitados em um leito de hospital" (2/2011/R 26).

Assim, buscamos auscultar, como Dostoiévski, as relações dialógicas como manifestações humanas e humanizadoras na dinâmica do "LabHum como uma cena - ou ato - em nossa vida" em seu percurso estético literário.

\section{Referências}

ALIGHIERI, Dante. A Divina Comédia. São Paulo: Editora 34, 2012.

BAKHTIN, Mikhail. O Problema da Poética em Dostoiévski. Rio de Janeiro: Forense Universitária, 1997.

BAKHTIN, Mikhail. Para uma Filosofia do Ato Responsável. São Carlos: Pedro \& João Editores, 2010.

BITTAR, Y.; SOUSA, M. S.; GALLIAN, D.M.C.. A experiência estética da literatura como meio de humanização em saúde: o Laboratório de Humanidades da Escola Paulista de Medicina, Universidade Federal de São Paulo., Interface (Botucatu), Botucatu, v. 17, n. 44, mar 2013. Disponível em < http://dx.doi.org/10.1590/S1414-32832013000100014>. Acesso em 3 jul 2013.

CALVINO, Ítalo. Assunto encerrado: discurso sobre literatura e sociedade. São Paulo: Companhia das Letras, 2006.

CALVINO, Ítalo. Por que ler os Clássicos. São Paulo: Companhia das Letras, 1993.

CARROLL, Lewis. Alice - Aventuras de Alice no Pais das Maravilhas: Através do Espelho e o que Alice Encontrou Por Lá. São Paulo: Zahar, 2012.

COMPAGNON, Antoine. Literatura para quê? Belo Horizonte: Editora UFMG, 2009.

CONRAD, Joseph. O Coração das Trevas. São Paulo: Iluminuras, 2007.

FINKIELKRAUT, Alain. Um Coração Inteligente. Rio de Janeiro: Civilização Brasileira, 2011. FORBES, Jorge. O Chato e o poeta. In: Psique - Ciência e Vida, São Paulo, Editora Escala, n. 58, outubro 2010.

FREUD, Sigmund. (2006). Escritores Criativos e Devaneio. (1908 [1907]) (Edição standard brasileira das obras psicológicas completas de Sigmund Freud, Vol. IX). Rio de Janeiro: IMAGO. 
GALLIAN, D. M. C.; PONDÉ, L. F. . RUIZ, R. Humanização, Humanismos e Humanidades: Problematizando Conceitos e Práticas no Contexto da Saúde no Brasil. Revista Internacional de Humanidades Médicas, Madrid, España, v. 1, n.1, p. 5-15., 2012. Disponível em < http://salud-sociedad.com/publicaciones/revista>. Acesso em ago 2012.

GOETHE, Johann. Wolfgang. Os Anos de Aprendizado de Wilhem/m Meister. São Paulo: Editora 34, 2009.

HUXLEY, Aldous. Admirável Mundo Novo. São Paulo: Globo, 2009.

KAZANTZAKIS, Nikos. Zorba, o grego. São Paulo: Editora Círculo do Livro, 1973.

PONDÉ, Luiz Felipe. Crítica e Profecia: a Filosofia da Religião em Dostoiévski. São Paulo:

Editora 34, 2003.

RODRIGUES, Nelson. Vestido de Noiva. In: Teatro completo de Nelson Rodrigues: Peças

Psicológicas. v. 1. Rio de Janeiro: Nova Fronteira, 2004.

STEINER, George. Tolstói ou Dostoiévski. São Paulo: Perspectiva, 2006.

TARKOVSKI, Andrei. Esculpir o Tempo: Tarkovski. São Paulo: Martins Fontes, 1998.

TODOROV, Tzvetan. A Literatura em Perigo. Rio de Janeiro: DIFEL, 2010.

Submetido em: 30-11-2015

Aprovado para publicação: 04-08-2016 